\title{
The effect of liner design and materials selection on prosthesis interface heat dissipation
}

\author{
Authors: Rhys J. Williams, Elaine D. Washington, Mark Miodownik, Catherine Holloway.
}

Background and aim: Thermal discomfort often affects prosthesis wearers and could be addressed by increasing liner thermal conductivity. This note explores a liner made from thermally conductive silicone and two additional alternative liner designs.

Technique: Thermally conductive silicone was used to create a conductive liner and a hybrid liner. Additionally, one with open elements was made. These were compared with a plain silicone liner and a no liner scenario. Scaled down liner prototypes were used due to the high-cost of the thermally conductive silicone. Temperature decay profiles were collected by attaching thermistors to a heated liner phantom and used to evaluate scenarios.

Discussion: No scenario performed much better than the plain silicone liner. Implementation of passive solutions may be easier, but alternative liner materials are unlikely to affect dissipation enough to address thermal discomfort. Based on this work, future research efforts may be better spent developing active thermal discomfort solutions.

Clinical relevance: Thermal discomfort can increase the probability of skin damage, reduce prosthesis satisfaction and, ultimately, the quality of life. The prosthesis-wearing experience could be improved if thermal discomfort can be addressed by technological improvements.

\section{BACKGROUND AND AIM}

Lower limb prosthesis wearers often report a moderate level of satisfaction with their artificial limbs; listing excess sweating, foul odors, and sounds as their top 3 annoyances. ${ }^{1}$ Thermal discomfort is highly prevalent among prosthesis wearers, affecting more than $53 \%$ of all amputees. ${ }^{2}$ In lower limb prosthesis wearers, even light exercise causes an increase in temperature of the skin-prosthesis interface ${ }^{3-7}$ that dissipates away slowly. ${ }^{3,5,7}$ Prosthesis impermeability means sweat cannot evaporate, and when this hot 
and sweaty interface is subjected to ambulation forces, skin damage can rapidly occur. ${ }^{6,8-11}$

Components that aim to minimize or delay heat and sweat discomfort are emerging, ${ }^{12,13}$ but more studies are required to comprehensively determine their efficacy. ${ }^{14,15}$ Klute et al. ${ }^{16}$ suggested that increasing the thermal conductivity of interface components could improve heat transport and suggested that the liner material has a greater effect on skin temperature, in comparison to the socket component as it is thinner.

This note explores potential liner design solutions in response to lower limb thermal discomfort. To evaluate potential designs, an easy-to-implement experimental method is described. Most importantly, by investigating a liner material with a higher thermal conductivity, this article progresses prosthetic thermal discomfort research.

\section{TECHNIQUE}

Thermally conductive and plain silicone were used to create liner scenarios called the mini thermal liner (MTL) which was made using thermally conductive silicone, the mini open liner (MOL) which was made using plain silicone, and a mini hybrid liner (MHL) which was made using both plain and thermal silicone (Figure 1(a)). These were compared to a mini 'plain' silicone liner (MPL) and a no-liner scenario. Commercially available elastomeric materials with thermal conductivities above $0.266 \mathrm{~W} / \mathrm{m}^{\circ} \mathrm{C}$, and Shore 00 hardness between 0 and 60 were sourced (Table 1). Existing liners have conductivities lower than this ${ }^{16}$ and similar hardness. Silcotherm materials (ACC Silicones, UK) were the only candidates near these criteria, with SE2010 meeting them exactly. Only liquid samples of SE2010 could be sourced 
at a cost of nearly $£ 70 / 50 \mathrm{~mL}$. The high cost meant that mini liner designs were preferred over full-sized prototypes, as this was not believed to significantly alter the underlying thermodynamics. The prototypes were designed to be a simplified anatomical shape, to enable a realistic liner donning procedure. Prototypes were digitally designed, threedimensional (3D) printed, and cast in the appropriate material (Table 1). SE2010 was difficult to mold, which meant that the MTL required minor surface repairs that added up to $1 \mathrm{~mm}$ to the thickness in those locations (Figure 1(a)). 


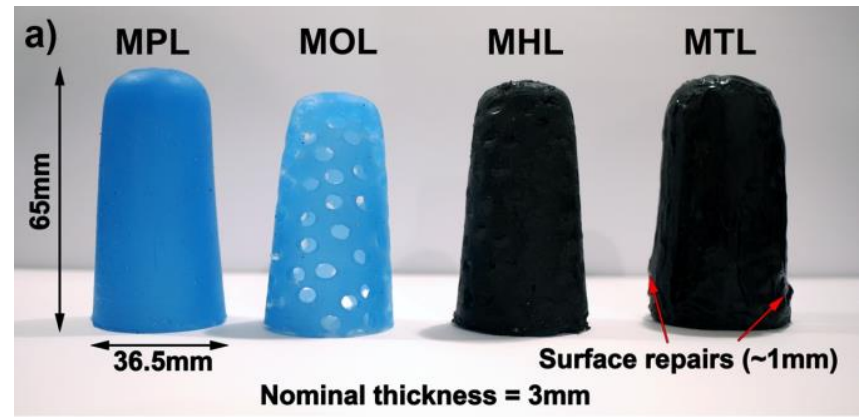

b)

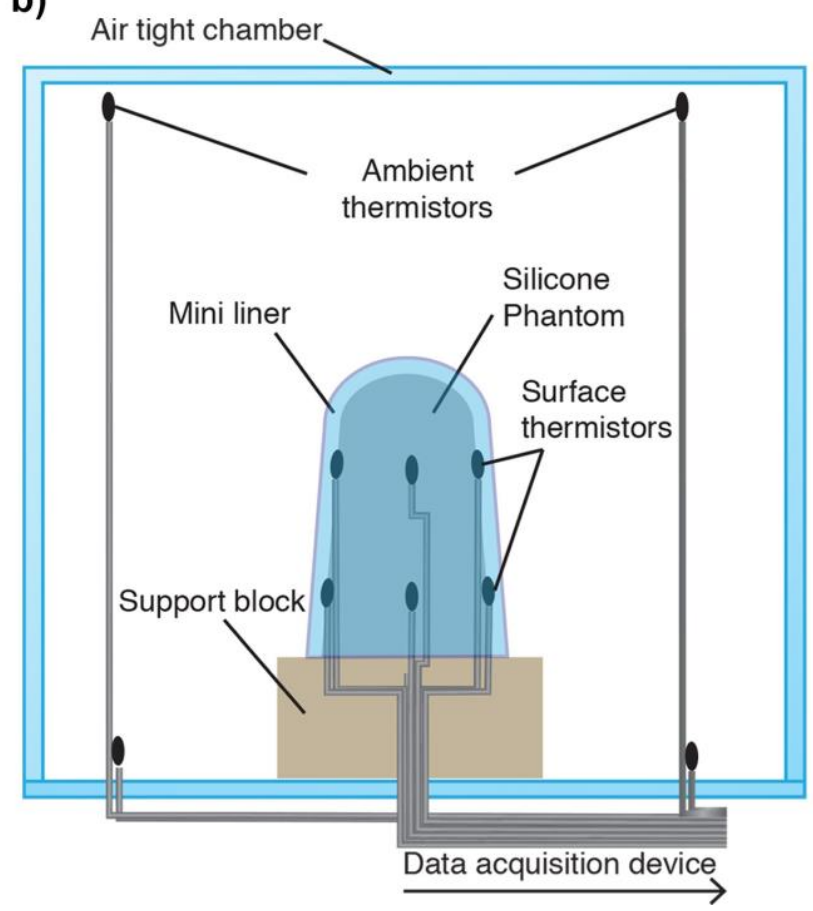

Figure 1: a) Scaled-down liners were used to test the mini plain liner (MPL) made from standard silicone, mini open liner (MOL) featuring 30\% surface perforations, mini hybrid liner (MHL) featuring 30\% conductive silicone and 70\% plain silicone, and min i thermal liner (MTL) which was $100 \%$ thermally conductive silicone and (b) a silicone tissue phantom was instrumented with thermistors and sealed in an acrylic box during experiments for each liner scenario.

Table 1: Silcotherm materials are potential liner material candidates as they feature a high thermal conductivity and could be moulded. Only SE2010 was purchasable. DragonSkin 10 was also used for any low-conductivity parts, though the thermal conductivity of this is unknown. It is likely to be between $0.14-0.35 \mathrm{~W} / \mathrm{m}^{\circ} \mathrm{C}$ however ${ }^{20}$. Materials in bold were used in this note. 


\begin{tabular}{lll}
\hline Material & $\begin{array}{l}\text { Thermal conductivity } \\
\left(\mathrm{W} / \mathrm{m}^{\circ} \mathrm{C}\right)\end{array}$ & Shore 00 Hardness \\
\hline Silcotherm SE2010 & $\mathbf{1 . 7}$ & $\mathbf{5 0}$ \\
Silcotherm SE2020 & 2.0 & 52 \\
Silcotherm SE2021 & 2.0 & 52 \\
\hline DragonSkin 10 & Not provided & $\mathbf{5 5}$ \\
\hline \hline
\end{tabular}

Due to the early stage of this project, a controlled silicone limb phantom was used to test the effect of each liner scenario on heat decay, rather than an amputee's residual limb. This removed physiologically related temperature variations ${ }^{16}$ which would have been difficult to control. This ensured a consistent base thermal decay profile for each experiment. Microwave heating was used as it quickly heated the phantom volume, not just the surface, and has been used previously to heat limb phantoms. ${ }^{18}$ The homogeneity of the silicone phantom meant surface temperature was approximately the same over the entire surface. This differs from residual limbs, which have locational temperature differences due to anatomical features. ${ }^{4}$ This extra layer of control meant that the average of surface temperature data could be used in the analysis. Data were collected with an Arduino Mega 2560 (Arduino, Italy), as it supported 16 analog inputs, which were connected to sixteen 10-k $\Omega$ B57863S103F40 negative temperature coefficient (NTC) thermistors (Epcos, Germany). The Arduino was interfaced and programmed using LabVIEW 2015 (National Instruments, USA) and the LabVIEW LINX interface. Data were acquired at $2 \mathrm{~Hz}$ and stored on a connected laptop. This acquisition rate is above the thermoregulatory response time, which is an order of multiple seconds ${ }^{19}$ and lies within the range of other prosthesis temperature studies $\left(0.125-4 \mathrm{~Hz}^{3,5,6}\right)$. Thermistors were each connected to a standard bridge circuit, supplied by a 5-V direct current (DC) laboratory power supply and calibrated using the Steinhart-Hart equation, resulting in an accuracy of $\pm 0.2^{\circ} \mathrm{C}$ between $0^{\circ} \mathrm{C}$ and $70^{\circ} \mathrm{C}$. Once collected, data were analyzed using MATLAB 2016a (Mathworks, USA). 
The phantom was irradiated for $45 \mathrm{~s}$ in a category D 700-W microwave and eight thermistors were attached using Kapton tape (DuPont USA) and evenly spaced around the perimeter of the phantom, with four on the upper and lower halves respectively (Figure 1(b)). Room temperature liners were rolled over the therm istors and phantom, and then placed into an acrylic box (Figure 1(b)), and data were collected for 35 min. The time from removing the phantom, post-heating, to donning the liners was under $30 \mathrm{~s}$. Thermal grease was not applied to maintain similarity with the natural prosthesis interface. Eight thermistors recorded ambient conditions inside the box, and each scenario was repeated seven times to enable easy recognition of anomalous data, though the number of repetitions is arbitrary. After microwaving, the phantom was much hotter $\left(>50^{\circ} \mathrm{C}\right)$ than skin. Thus, when the phantom registered $33.0^{\circ} \mathrm{C} \pm 0.1^{\circ} \mathrm{C}$, the time was recoded as $t=0$, to represent the highest temperature found post-exercise for transtibial amputees, in three studies ${ }^{3,5,6}$ to the nearest integer. The average of phantom surface and ambient data was calculated (one ambient thermistor broke and was excluded). Despite the airtight chamber, some coupling existed between ambient and phantom surface data.

$$
K=\sum_{\&-,}^{)_{+}^{+}}\left(T_{\&}-T_{\&()}\right)
$$

To remove this coupling, the difference between surface and ambient temperature data was calculated. Equation (1) was used to find the surface temperature decay, $P$, after a noise reducing 60-s moving average filter was applied (filter window $=120$ samples at a collection rate of $2 \mathrm{~Hz}$ ). This metric shows changes in phantom surface temperature in 1 min during the experiment.

\section{RESULTS AND DISCUSSION}

First-degree polynomial correlations were extracted from the data after applying equation (1). The combined data sets make it possible to see the effect of the liners on phantom 
surface temperature decay (Figure 2). The no-liner scenario demonstrated the greatest decay per minute, per ${ }^{\circ} \mathrm{C}$ of ambient-phantom temperature difference.

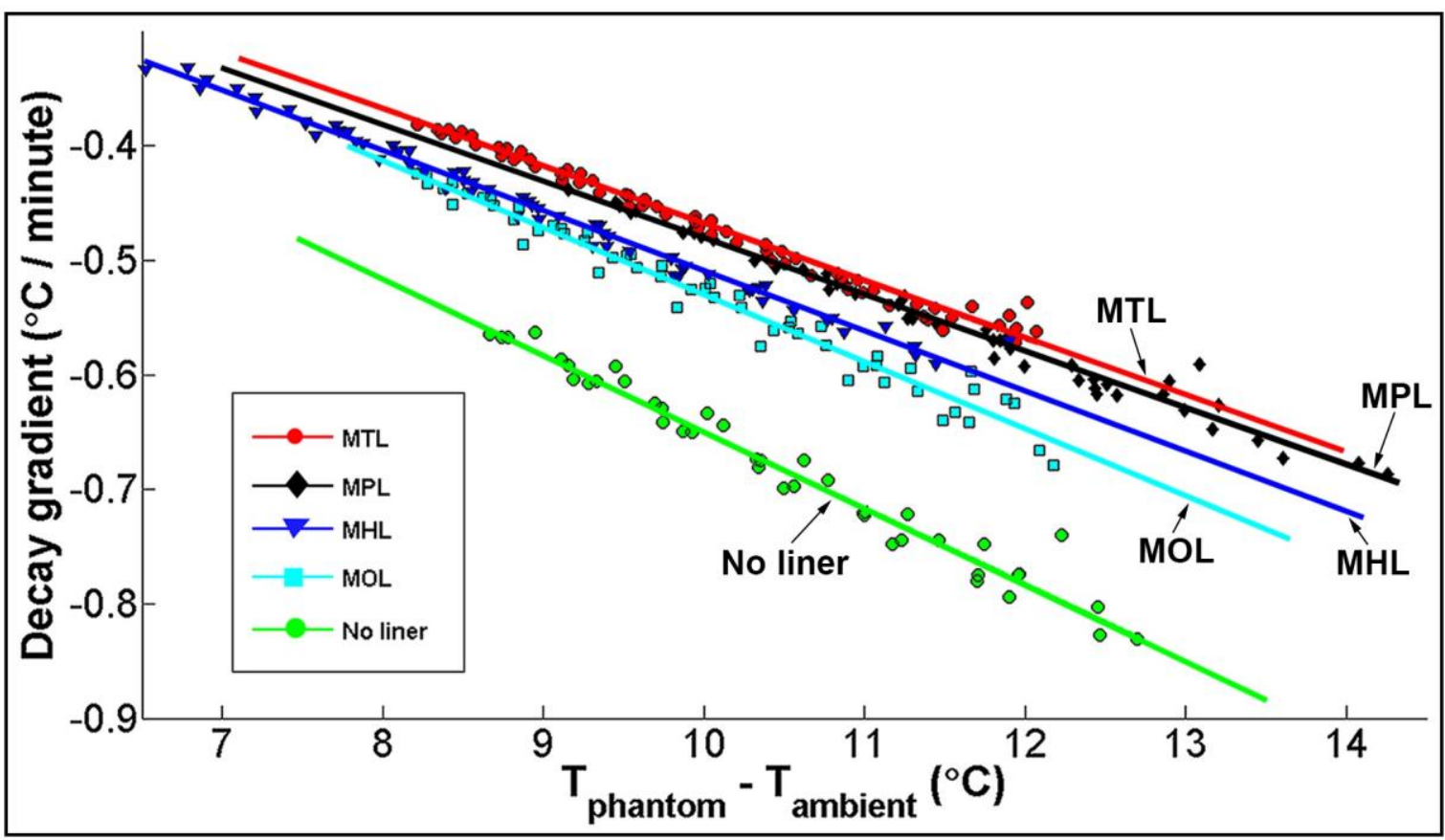

Figure 2: Data from all of the scenarios were plotted, and the gradient of each was subsequently extracted.

With ambient coupling removed, the MHL had superior dissipation performance over the MPL; however, only the MOL had a gradient close to the no-liner scenario. To contextualize the data in Table 2, if the MOL was used in an ambient temperature of $20^{\circ} \mathrm{C}$, with a phantom surface temperature of $30^{\circ} \mathrm{C}$, the phantom surface could decrease by $0.6^{\circ} \mathrm{C} / \mathrm{min}$. Open elements were the most effective at increasing heat decay; however, an open liner design with large open elements, such as those on the MOL, may reduce suspension and durability. ${ }^{20,21}$ Additionally, although there are liners on the market with small 
perforations, ${ }^{13}$ large open elements may also introduce high shear stresses that could harm skin.

Table 2: The dissipation gradient for each scenario's correlation is presented. All fits possess a high coefficient of determination $\left(R^{2}\right)$ and evenly distributed residual plots.

\begin{tabular}{llllll}
\hline & No Liner & $\mathrm{MOL}$ & $\mathrm{MPL}$ & $\mathrm{MHL}$ & $\mathrm{MTL}$ \\
\hline Dissipation per minute, per $\Delta \mathrm{T}$ & -0.07 & -0.06 & -0.05 & -0.05 & -0.05 \\
$\mathrm{R} 2$ & 0.97 & 0.97 & 0.99 & 0.98 & 0.98 \\
\hline \hline
\end{tabular}

Increased thermal conductivity has been suggested as a way to improve heat dissipation in liners; ${ }^{16}$ this study indicates that it may not effectively minimize or prevent thermal discomfort for lower limb prosthesis wearers. There are caveats to this conclusion: surface repairs of the MTL may have affected heat dissipation, but as these were minor and isolated, this is unlikely to significantly affect this finding. The applied technique also did not include a simulated socket layer which is an interface layer with a low thermal conductivity. However, they are thinner than liner components and will, therefore, have a smaller impact on heat dissipation in comparison to liners. ${ }^{16}$ The thermodynamic properties of the phantom may also differ from human tissue, but it provided a consistent heat decay profile necessary for evaluation. Finally, as this experiment was informed by studies that only recruited transtibial amputees, ${ }^{3,5,6}$ an appropriate level of caution must be applied when extrapolating findings to other lower limb amputee populations. This highlights an important reminder that future thermal discomfort studies should actively seek to recruit 
participants with varying levels of amputations, including both unilateral and bilateral amputees to broaden understanding of the phenomenon. To conclude, this note suggests that in scaled-down liner scenarios, passive heat transport solutions are unlikely to improve heat decay at a simulated prosthesis interface. Unless the thermal conductivity of elastomers can be increased beyond the elastomers used here, or suspension liners are radically rethought, active solutions used in the study of Han et al. ${ }^{22}$ and Ghoseiri et al. ${ }^{23}$ may be a more promising avenue to mitigate and prevent thermal discomfort for prosthesis wearers.

KEY POINTS

- Increasing thermal conductivity of liners was suggested by Klute et al. ${ }^{16}$ as a potential solution to prosthesis heat and sweat discomfort.

- The only viable commercially available material found had a thermal conductivity of $1.7 \mathrm{~W} / \mathrm{m}^{\circ} \mathrm{C}$ and a Shore 00 hardness of 50 .

- Experiments revealed that of the four scaled-down liner scenarios proposed, only the open liner notably improved heat decay but may be impractical due to mechanical and durability issues.

- Active cooling solutions may present a more promising research direction in the future, in favor of increasing the thermal conductivity of prosthetic components.

FUNDING 
The author(s) disclosed receipt of the following financial support for the research, authorship, and/or publication of this article: Rhys Williams is funded by the UCL Doctoral

Training Programme in Medical Device Innovation. This programme is funded by UCL, EPSRC Doctoral Training Grants and the National Institute for Health Research, University College London Hospitals, Great Ormond Street Hospital and Moorfields Eye Hospital Biomedical Research Centres.

\section{REFERENCES}

1. Ali S, Abu Osman NA, Naqshbandi MM, et al. Qualitative study of prosthetic suspension systems on transtibial amputees' satisfaction and perceived problems with their prosthetic devices. Arch Phys Med Rehabil 2012; 93: 1919-1923.

2. Ghoseiri K, Safari MR. Prevalence of heat and perspiration discomfort inside prostheses: literature review. J Rehabil Res Dev 2014; 51: 855-868.

3. Peery JT, Ledoux WR, Klute GK. Residual-limb skin temperature in transtibial sockets. J Rehabil Res Dev 2005; 42: 147-154.

4. Peery JT, Klute GK, Blevins JJ, et al. A three-dimensional finite element model of the transibial residual limb and prosthetic socket to predict skin temperatures. IEEE Trans Neural Syst Rehabil Eng 2006; 14: 336-343.

5. Huff EA, Ledoux WR, Berge JS, et al. Measuring residual limb skin temperatures at the skinprosthesis interface. J Prosthet Orthot 2008; 20: 170-173.

6. Klute GK, Huff E, Ledoux WR. Does activity affect residual limb skin temperatures? Clin Orthop Relat Res 2014; 472: 3062- 3067.

7. Mathur N, Glesk I, Buis A. Skin temperature prediction in lower limb prostheses. IEEE J Biomed Health Inform 2016; 20: 158-165.

8. Hoaglund FT, Jergesen HE, Wilson L, et al. Evaluation of problems and needs of veteran lower-limb amputees in the San Francisco Bay Area during the period 1977-1980. J Rehabil Res Dev 1983; 20: 57-71. 
9. Levy SW. Amputees: skin problems and prostheses. Cutis 1995; 55: 297-301.

10. Highsmith JT, Highsmith MJ. Common skin pathology in LE prosthesis users. JAAPA 2007; 20: 33-36.

11. Meulenbelt HE, Geertzen JH, Dijkstra PU, et al. Skin problems in lower limb amputees: an overview by case reports. J Eur Acad Dermatol Venereol 2007; 21: 147-155.

12. WillowWood. Alpha SmartTemp ${ }^{\circledR}$ Liner Featuring Outlast $^{\circledR}$, https://www.willowwoodco.com/productsservices/liners/transtibial/alpha-smarttempliner-featuring-outlast/ (accessed 18 October 2016).

13. Blatchford. Silcare breathe-liners-prosthetic catalogue, http://www.blatchford.co.uk/endolite/silcare-breathe-liner/ (accessed 18 October 2016).

14. Wernke MM, Schroeder RM, Kelley $\mathrm{CT}$, et al. SmartTemp prosthetic liner significantly reduces residual limb temperature and perspiration. J Prosthet Orthot 2015; 27: 134-139.

15. Ghoseiri K, Zheng YP, Leung AKL, et al. Temperature measurement and control system for transtibial prostheses: functional evaluation. Assist Technol 2016; 3: 1-8.

16. Klute GK, Rowe GI, Mamishev AV, et al. The thermal conductivity of prosthetic sockets and liners. Prosthet Orthot Int 2007; 31: 292-299.

17. Lasance CJM. The thermal conductivity of rubbers/elastomers "Electronics Cooling Magazine-Focused on Thermal Management, TIMs, Fans, Heat Sinks," CFD Software, LEDs/Lighting, http://www.electronics-cooling.com/2001/11/the-thermalconductivity-ofrubbers-elastomers/ (2001, accessed 1 October 2016).

18. Ho HS, Guy AW, Sigelmann RA, et al. Microwave heating of simulated human limbs by aperture sources. IEEE T Microw Theory 1971; 16: 224-231.

19. Romanovsky AA. Skin temperature: its role in thermoregulation. Acta Physiol 2014; 210: 498-507.

20. Nakamura TOA, Hatano EMD. Process of development and application of porous plastic to prosthetic sockets. J Prosthet Orthot 1989; 1: 202-210.

21. Foort J. The patellar-tendon-bearing prosthesis for below-knee amputees, a review of technique and criteria. Artif Limbs 1965; 13: 4-13.

22. Han Y, Liu F, Dowd G, et al. A thermal management device for a lower-limb prosthesis. Appl Therm Eng 2015; 82: 246-252. 
23. Ghoseiri K, Zheng YP, Hing LLT, et al. The prototype of a thermoregulatory system for measurement and control of temperature inside prosthetic socket. Prosthet Orthot Int 2015; 40: 751-755. 